\title{
The practice of phenomenology: The case of Max van Manen
}

\section{Abstract}

Since its inception, phenomenological philosophy has exerted an influence on empirical science. But what is the best way to practice, use and apply phenomenology in a non-philosophical context? How deeply rooted in phenomenological philosophy must qualitative research be in order to qualify as phenomenological? How many of the core commitments of phenomenology must it accept?

In the following contribution, I will take a closer look at Max van Manen's work. I will argue that van Manen's understanding of and presentation of phenomenology is quite problematic and that his book Phenomenology of Practice rather than amounting to a clear and accessible presentation of the phenomenological method that would make it do-able to researchers who are not themselves professional philosophers is in fact both abstruse and excessively complicated.

I will then turn to nursing, and by taking that as my example, outline a better way to apply and practice phenomenology.

Since its inception, phenomenological philosophy has exerted an influence on empirical science. Experimental psychology and psychiatry were among the first disciplines to take inspiration from Husserl's call to attend to the phenomena in their full concreteness. Already in 1912, Karl Jaspers published a short article outlining how psychiatry could profit from Husserlian phenomenology (Jaspers 1912), and in the following decades prominent psychologists and psychiatrists such as Katz, Schilder, Binswanger, Straus, Buytendijik and Minkowski all engaged with phenomenology in their practice and research. Whereas the interest in phenomenology among psychologists might 
have waned somewhat by the end of the fifties, it resurfaced within the domain of cognitive science in the 1990s after a number of influential publications by the Chilean neuroscientist Francisco Varela (Varela et al. 1991, Varela 1996, 1997). Varela argued that cognitive science would never be able to provide a scientific theory of consciousness if it merely studied subpersonal neurophysiological processes and he urged cognitive scientists to engage directly in a careful study of the qualities and structures of experience. Varela's publications generated a substantial and still ongoing discussion about the relation between phenomenology and the cognitive sciences (Petitot et al. 1999, Zahavi 2004, Gallagher 2005, Thompson 2007, Carel \& Meacham 2013). What does a phenomenological cognitive science look like? How deeply rooted does it have to be in phenomenological philosophy? How many of the core commitments of phenomenology does it have to accept? How heterodox can it be, while still qualifying as phenomenological?

Although the specific discussion in question has only to a quite limited extent affected debates within qualitative research, many of the questions should be quite familiar to qualitative researchers since a similar debate has taken place between Amedeo Giorgi, Jonathan Smith and Max van Manen, three of the leading proponents of phenomenology as a qualitative research method. All three enjoy wide popularity and are routinely referenced by qualitative researchers, but they differ in their methodological recommendations and in their view of how narrowly or broadly one should define what counts as phenomenological. Must phenomenological qualitative research embrace and adopt part of Husserl's philosophical method, in particular his notions of epoché and reduction, or can it dispense with those notions and instead draw methodological inspiration from a variety of phenomenological authors? Might it even be sufficient simply to consider the first-person perspective of the informant in order to make the approach in question phenomenological? 
In one of his early texts on the topic, Smith explains that he chose the term Interpretative Phenomenological Analysis (IPA) for his own approach, since the aim of IPA is to "explore the participant's view of the world and to adopt, as far as is possible, an 'insider's perspective' of the phenomenon under study" (Smith 1996: 264). Smith also writes that IPA is a phenomenological approach "in that it involves detailed examination of the participant's lifeworld; it attempts to explore personal experience and is concerned with an individual's personal perception or account of an object or event, as opposed to an attempt to produce an objective statement of the object or event itself" (Smith and Osborn 2008: 53)

In a recent exchange between van Manen and Smith in Qualitative Health Research, however, van Manen has accused Smith of hijacking the term 'phenomenology' for his own type of psychological analysis (van Manen 2017a: 778). Although Smith does on occasion reference phenomenological authors, his use of phenomenology is, according to van Manen, far too shallow and superficial to qualify as phenomenological in the original sense of the term (van Manen 2017a: 778). As van Manen puts it,

not all qualitative research inspired by phenomenology is phenomenology. Pointedly, one must ask whether a study that makes claims to phenomenology actually practices the method of the epoché and the reduction implicitly or explicitly in philosophically appropriate or valid manner. It should be acknowledged that the various qualitative research methods that are inspired by phenomenology may be undeniably important and relevant and yet are not to be confused with genuine phenomenological methods and phenomenological research approaches (van Manen 2017a: 777). 
Van Manen has further argued that Smith's methodology is "hopelessly misrepresentative of phenomenology in any acceptable sense" (van Manen 2018: 1962), and that "the program of IPA does not resemble any of the phenomenologies that are to be found in the primary literature, tradition, and movements of phenomenology" (van Manen 2018: 1966). This might seem an overly aggressive criticism, but as van Manen explains, he has stepped up the fight against shallow understandings of phenomenology and decided to defend the phenomenological method in its original and authentic sense because an overly broad use of the term 'phenomenology' damages the reputation of phenomenology and erodes "the larger project of phenomenology in relation to professional practices in fields such as psychology, health science, education, and pedagogy" (van Manen 2018: 1966).

To a large extent, I share van Manen's criticism of IPA. Its link to philosophical phenomenology is so tenuous, that anybody practicing it, can only be said to be engaged in phenomenological research in the most superficial sense of the term. My goal in the following, however, will be to take a closer look at van Manen's own work on phenomenological research. His 1990 book Researching Lived Experience remains one of the most used sources with more than 20.000 citations. His 2014 book Phenomenology of Practice must be the most voluminous and encompassing treatment of phenomenological research by a qualitative researcher. It was recently praised as a book that distils "a lifetime of scholarship dedicated to understanding and explaining a phenomenology of practice" and as one that offers not only substantial clarifications of the central phenomenological concepts, but also contains a particularly enlightening treatment of what it actually means to do phenomenological research (Roulston 2018: 252).

\section{Back to the origins}


One of van Manen's repeated claims is that we should not make do with secondary literature, but rather return to the origin and consult "the primary literature, tradition, and movements of phenomenology" (van Manen 2018: 1966). His own grand oeuvre, Phenomenology of practice, is presented as a text whose account of phenomenology is derived "from the works and texts of leading phenomenological thinkers and authors" (van Manen 2014: 16). Based on his engagement with the writings of a whole range of influential figures in classical and contemporary phenomenological philosophy, van Manen has made some specific claims concerning 1) the aim of a phenomenological investigation and 2) the nature of the phenomenological method.

When it comes to the aim, van Manen claims that phenomenology is the study of the lived meaning of experience. To do phenomenological research is consequently to investigate what an experience is like (van Manen 1990: 42, 2017a: 776). Indeed, van Manen claims that the basic phenomenological question is the question of "What is that experience like?" (2014: 35, 2017b: 811), and he mentions questions such as "What is it like to sip coffee?" (2014: 35) and "What is it like to share looking at water from a bridge?" (2014: 35) as examples of core phenomenological questions.

When it comes to the method, van Manen insists that the "basic method of phenomenological analysis consists of the epoché and the reduction" (2017b: 820; cf. 2014: 27, 2018: 1962), and he argues that phenomenologists employ the epoché and the reduction precisely because this allows them to grasp "the phenomenological meaning of a human experience" (van Manen 2017b: 819).

Can both of these central and often repeated claims withstand closer scrutiny? Let us start with the latter claim, the claim that the basic method of phenomenology consists of the epoché and 
reduction. Is this correct? Is this something that all (or the large majority of) leading phenomenological philosophers would agree to? The short answer is no. Consider first Husserl's early work, the monumental Logical Investigations from 1900-01. This is the work that contains Husserl's first full-fledged investigation of intentionality. This is where we find Husserl insisting on the importance of carefully attending to the phenomena instead of being sidetracked by various theoretical prejudices and where we also find his famous slogan about the need to return to the 'things themselves' (Husserl 2001: I/168). Logical Investigations was a resounding success and basically triggered the launch of the phenomenological movement. The work, however, contains no reference to the epoché or the phenomenological reduction. These methodological notions and manoeuvres were simply not required in order to engage in the kind of descriptive phenomenology that was of concern to the early Husserl. When Husserl later in life introduced the epoché and reduction, he did so for quite different philosophical reasons. According to Husserl, a number of fundamental epistemological and metaphysical questions cannot be investigated in a sufficiently radical manner as long as we simply and unproblematically live in the natural attitude. In the natural attitude, we take it for granted that the world we encounter in experience exists independently of us. For Husserl, this basic and natural realism cannot be presupposed if we want to take philosophy seriously. Rather, it must be critically examined. In order to do so, however, we must first take a step back from our naïve and unexamined immersion in the world and suspend our automatic belief in the mind-independent existence of that world. More specifically, Husserl talks of how the epoché targets and suspends the general thesis (Generalthesis) that belongs essentially to the natural attitude (Husserl 1982: 61). By performing the epoché, by bracketing or suspending our tacit belief in the absolute (i.e., not mind-relative) existence of the world, we come to realize that subjects of experience are required if worldly objects are to appear with the validity 
and meaning that they have. When Husserl subsequently introduced the reduction, what he had in mind was precisely a systematic analysis of this correlation between world and subjectivity. Both the epoché and the reduction can consequently be seen as elements in a philosophical reflection, the purpose of which is to liberate us from our natural dogmatism and make us aware of our own constitutive accomplishment, make us realize to what extent consciousness, reason, truth, and being are essentially interlinked (Husserl 1982: 340, Zahavi 2003, 2019a).

Husserl's introduction of the epoché and reduction is closely linked to his transcendental turn, i.e., his turn towards transcendental philosophy and his increasing commitment to a form of transcendental idealism that insisted on reality and objectivity being dependent upon subjectivity (Zahavi 2015, Zahavi 2017). But this is by no means a commitment that was shared by all phenomenologists. Many of Husserl's early followers who took inspiration from his insistence on the importance of attending to things as they are encountered in experience saw no reason to introduce and carry out the epoché and the reduction. Consider, for example, the case of Adolf Reinach, one of the most talented early phenomenologists. Back in 1914, Reinach gave an influential introductory talk entitled "What is phenomenology?" Reinach began his lecture by saying that he didn't want to simply talk about phenomenology, rather together with the audience he wanted to do phenomenology. In the course of this exercise, Reinach insisted that phenomenology, rather than being a comprehensive system of philosophical propositions, was a specific method of philosophizing, a particular philosophical attitude. What characterizes this attitude? Its aim is to grasp the essence of the object under investigation, whereas its particularity is of no concern. Interestingly, Reinach by no means restricted the focus of phenomenology to an investigation of experiences, but mentioned that phenomenologists should also investigate time, space, numbers, concepts and propositions. Reinach concluded his lecture by arguing that the 
phenomenological return to "the things themselves" is a turning away from theories and constructions, in order to obtain a "pure and unobscured intuition of essences" (Reinach 1968). How many times did Reinach refer to the epoché and the reduction in his lecture? Not even once. The idea that phenomenology is primarily to be understood as a form of essentialism is not unique to Reinach. Max Scheler, another well-known phenomenologist, also understood the phenomenological method primarily as involving an intuition of essences, where one disregards the here and now of objects in order to focus on their essential features. For the same reason, Scheler strongly distanced himself from what he took to be Husserl's overly narrow focus on consciousness (Scheler 1973: 311).

What about later phenomenologists? It is indisputable that neither Heidegger nor MerleauPonty made many references to the epoché and the reduction. But it is a matter of an ongoing scholarly debate whether this is so because they rejected Husserl's methodology or because they simply took it for granted. It is not difficult to find interpreters who think that the hermeneutic phenomenology of Being and Time amounts to a wholesale rejection of Husserl's phenomenological method (Carman 2003), or that Merleau-Ponty's work was antithetical to Husserl's (Dwyer 1990). I happen to think both claims are wrong, but in order to show why, a detailed and careful analysis is required. The matter is even more complicated when it comes to some of the other phenomenologists that van Manen discusses in Phenomenology of practice, including, e.g., Sartre, de Beauvoir, Arendt or Dreyfus. Sartre only mentions the epoché once in Being and Nothingness and that is in order to distance himself from it (Sartre 2018: 370). The same holds true for the few occasions where Sartre mentions Husserl's phenomenological reduction. As for Dreyfus, he has for years derided both notions (e.g., Dreyfus 1991: 73, Dreyfus 1993). To insist that the epoché and the reduction is the basic method of phenomenology is consequently a fairly 
controversial claim. Perhaps the claim is true. Perhaps it is indeed the case that the epoché and the reduction are crucial to phenomenology and that both notions are operative in the work of phenomenologists who don't mention them. But this is certainly not something that can simply be taken for granted. Rather it would have to be backed up by substantial arguments and careful textual analysis, neither of which we find in the work of van Manen.

Saying all of this is certainly not to question the claim that the epoché and reduction play an absolutely fundamental role in the work of the later Husserl. For him, they were indeed essential to phenomenological philosophizing. But is this then because Husserl thought they were indispensable if one wants to provide a careful description of "what the experience is really like"? Is Husserl's work really devoted to this kind of descriptive analysis? The short answer is once again no. Indeed, had this been what Husserl was up to, it is questionable whether he would be doing philosophy at all, and he certainly wouldn't have had the massive impact of $20^{\text {th }}$-century philosophy that he in fact had. What topics did Husserl focus and work on? A quick glance in works like Ideas I (1913), Formal and transcendental logic (1929), Cartesian meditations (1931) and Crisis (1936) will see Husserl preoccupied with topics such as truth, reason, reality, ontology, science and objectivity. Certainly, Husserl throughout also argued that topics like these can only be philosophically clarified and understood if we take subjectivity and experience seriously. But to focus only on subjective experience and to ignore the philosophical questions that Husserl was trying to address is to miss the nature of his philosophical project.

Given what has been said so far, how should we then assess van Manen's first major claim, the claim that the proper target of a phenomenological investigation is the investigation of human consciousness and that the central and fundamental phenomenological question is "What is this lived experience like?" (van Manen 2017a: 776). As I have just pointed out, both Reinach and 
Scheler would strongly disagree and would consider the proposal a blatant and fatal subjectivization of phenomenology. As for Husserl, his mature phenomenology is also not primarily (and certainly not exclusively) interested in or preoccupied with the essential structures of experiences. It is just as much interested in the appearing world, i.e., in the world as it is experienced and understood by us. In fact, the aim of Husserl's phenomenological analysis is precisely not to investigate either the subject or the object, either the mind or the world, but to investigate both in their interrelation or correlation. As Husserl already writes in The Idea of Phenomenology 'The meaning of the word 'phenomenon' is twofold because of the essential correlation between appearing and that which appears" (Husserl 1999: 69). This is also why, say, a phenomenology of knowledge is concerned both with the experiences in which the objects are presented as well as with the objects themselves precisely as they are given (Husserl 1999: 69). That this twofold focus is absolutely crucial to Husserl was something he explicitly emphasized in a central passage in Crisis:

The first breakthrough of this universal a priori of correlation between experienced object and manners of givenness (which occurred during work on my Logical Investigations around 1898) affected me so deeply that my whole subsequent life-work has been dominated by the task of systematically elaborating on this a priori of correlation (Husserl 1970: 166)

The focus of phenomenology is on the intersection between mind and world, neither of which can be understood in separation from each other. To speak more concretely, a phenomenological investigation of a perceptual experience or an experience of fear must also 
investigate the intentional correlate, the perceived or feared object. To suggest that only the former is within the purview of phenomenology, to suggest, as van Manen does, that Husserlian phenomenology is not concerned with the external object, but only with our experience of the external object - that it doesn't "study the 'what' of our experience but the 'experience' of the what" (van Manen 2014: 91), is to misunderstand Husserl's project.

Many tend to equate the experience and the phenomenon. But, as Crotty argues in an early discussion of the use of phenomenology within nursing research, we should distinguish the subjective experiences from the phenomena being experienced, that is, we should distinguish the intentional experiences from the intentional objects (Crotty 1996: 17). To insist that phenomenology is only concerned with the former is to misunderstand the concept of intentionality and the very nature of the phenomenological enterprise. If we turn to van Manen, we will see that he frequently makes that very mistake. As he writes in Phenomenology of Practice: "Simply put, the thing or phenomenon for the researcher is a certain experience, a sensibility" (2014: 50), and "Phenomenology is the study of the phenomena, and the phenomena are someone's experiences" (2014: 91). Admittedly, one can also find van Manen asserting that "phenomenology studies the world as we ordinarily experience it" (2014: 65), and that the "lifeworld, the world of everyday lived experience, is both the source and the object of phenomenological research" (2014: 313), but this just demonstrates how unclear his presentation is, since the lifeworld, the world of experience, is obviously not itself an experience. ${ }^{1}$

I have on a previous occasion criticized van Manen's understanding of phenomenology (Zahavi 2019b). van Manen's subsequent reaction was both interesting and revealing. In his reply, he introduced a distinction between what he calls philosophical phenomenology and phenomenological philosophy (2019: 6). Whereas the first explores concrete phenomena such as 
pain, falling asleep, or reading a novel, the latter studies the nature of philosophical concepts in a phenomenological manner (2019: 6). In parallel, van Manen insisted on distinguishing those who actually do phenomenology, e.g., by writing phenomenologically about concrete lifeworld phenomena, and those who simply engage in the relative sterile work of exegetical philosophical theorizing (2019: 3). Whereas the latter work might be philosophically intricate, it is, according to van Manen, often conceptually cramped and lacking "a sense of thoughtful epiphanic significance" and therefore of little relevance to ordinary people as well as to professionals in nursing, clinical psychology, medicine etc. who might otherwise have an interest in phenomenology (van Manen 2019: 10-11). By introducing these distinctions, van Manen is consequently able to side-track criticisms from "learned scholars" whose interpretation of phenomenology differs from his own by claiming that, despite their theoretical knowledge, they are unable or unwilling "to look phenomenology in the face" (van Manen 2019: 3). In short, whereas van Manen in his dispute with Smith has insisted on the importance of returning to the classical philosophical texts and criticized Smith for engaging in a too shallow and superficial manner with the classical authors, van Manen changes strategy and instead expresses a distrust in theorizing and conceptual philosophical arguments (2019: 4) when confronted with criticism from phenomenological philosophers.

I think van Manen's position is inconsistent. I think it would be better if he simply conceded that the difference between himself and Smith is considerably smaller than he has made it out to be. When Smith in the past has been accused of practicing a kind of phenomenology that had little in common with what the philosophers meant by it, he defended himself by retorting that "philosophy does not own phenomenology" (Smith, Flowers, Larkin 2009: 32-33). van Manen's reply is a version of the same strategy. 


\section{Accessibility and applicability}

At this stage, however, we shouldn't lose sight of the central question. What is the best way to practice, use and apply phenomenology in a non-philosophical context? van Manen might not be an expert on phenomenological philosophy, but perhaps his factual errors and misinterpretations are ultimately of minor importance. Perhaps the really important question is whether he has succeeded in presenting phenomenology in a manner that is accessible to non-specialists and which provides them with methodological guidelines that can be used in practice and are conducive to high quality work in their respective fields. This certainly seems to be a clear goal of van Manen's, since he on repeated occasions has stressed the importance of not presenting the project and methodology of phenomenology in an overly technical manner (van Manen 2017b: 810). Indeed, Phenomenology of Practice clearly finds it important to make "phenomenological philosophy accessible and do-able by researchers who are not themselves professional philosophers or who do not possess an extensive and in-depth background in the relevant phenomenological philosophical literature" (van Manen 2014: 18). Might this be where van Manen's real accomplishment is to be found? If one looks at chapter 8 in Phenomenology of Practice - a work that, as already mentioned, has been praised as offering not only substantial clarifications of the central phenomenological concepts, but as also containing a particularly enlightening treatment of what it actually means to do phenomenological research - one is, however, in for a surprise. In this chapter on philosophical methods, van Manen doesn't merely present the reader with the distinction between the epoché and reduction. On the basis of his reading of the phenomenological philosophical literature, van Manen finds it necessary to distinguish the "following methodical moments of the epoché-reduction: the heuristic reduction, the hermeneutic reduction, the 
experiential reduction, and the methodological reduction" (van Manen 2014: 222). These are, however, only preparatory elements of the reduction proper. The latter comes in five varieties: "the eidetic, ontological, ethical, radical, and originary reduction" (van Manen 2014: 222). This brings us up to nine reductions in total. Is the proposal then that professionals in nursing, clinical psychology, medicine etc. should master all nine in order to do phenomenological research? Even if they could somehow manage to keep track of the differences, we have unfortunately not yet reached the end of the methodological complications. After having outlined the nine reductions, van Manen proceeds to discuss the revocative, evocative, invocative, convocative and provocative method (van Manen 2014: 240-296), and then moves on to differentiate the following heuristic moves: reduction, deduction, induction, preduction, production, abduction and seduction (van Manen 2014: 344). By including the latter, van Manen might unwittingly have hit the nail on the head. Not only do I think van Manen himself has been seduced by language, I also think anybody who believes that van Manen has offered a clear and enlightening account of what it means to do phenomenological research must have been seduced by his verbosity.

There are multiple problems with van Manen's presentation. To start with, it certainly doesn't amount to a non-technical and easily accessible introduction to phenomenological philosophy which will make it "do-able by researchers who are not themselves professional philosophers" (van Manen 2014: 18). In addition, from a theoretical point of view, van Manen's presentation is faced with two major weaknesses. The first is that many of the distinctions, rather than being solidly rooted in and based on the original texts, are van Manen's own inventions. The second is that although some of the notions might indeed be traced back to the works of, say, Husserl, Heidegger, Levinas or Marion, van Manen is not sufficiently attentive to all the internal tensions and theoretical incompatibilities that exist between the work of these phenomenologists. 
Perhaps it is possible to reconcile, say, the ontological and the ethical reduction, despite Levinas' expressed reservations. Perhaps it is possible to fashion a systematic integrative fusion of all the different phenomenological contributions. To do so would be a major theoretical accomplishment; a real contribution to the phenomenology of the $21^{\text {st }}$ century. But, unfortunately, that is not what van Manen has done. Rather, he offers a confused mishmash that ultimately erodes the reputation of the very tradition he takes himself to be defending.

In all fairness, it should be added that van Manen has also provided a different set of suggestions about how to carry out phenomenological research. In both Researching Lived Experience and Phenomenology of Practice, van Manen points to certain fundamental existential themes - including spatiality, sociality, temporality, corporeality etc. - that he claims can be found in the lifeworlds of all human beings, regardless of their historical, cultural, or social situatedness, and which he believes can prove especially helpful as focus points in the research process (van Manen 1990: 7, 2014: 302-307). It is a pity that van Manen entrenched this reasonable idea in a philosophically confused discussion of nine reductions, five methods and seven heuristic moves.

\section{Phenomenology in practice}

As I mentioned in the beginning, for the past 25 years, there has been an ongoing debate within the cognitive sciences (including developmental psychology, cognitive psychology, psychiatry, neuroscience, systems theory, and biology) about how best to employ and apply tools and concepts from phenomenology to the investigation of a range of topics including narrative identity, prereflective experience, mental imagery, action coordination, embodied habits, social cognition, skillful coping, emotions, collective intentionality etc. (Varela et al. 1991, Petitot et al. 1999, 
Gallagher 2005, Zahavi 2005, Thompson 2007, Ratcliffe 2008, Gallagher and Zahavi 2012, Zahavi 2014, Colombetti 2014, Fuchs 2017). Might some of the lessons learnt and conclusions drawn perhaps also be of relevance when it comes to the question of how best to practice phenomenology in the domain of qualitative research? I believe the answer is affirmative. Let us consider nursing as a case in point.

What might a phenomenology of nursing look like? According to Crotty, a phenomenology of nursing is basically an investigation of nursing as a phenomenon, i.e., an exploration of how nursing appears to us in our experience of it (Crotty 1996: 158-159). But surely there is more to phenomenology of nursing than that. Consider by comparison phenomenological psychiatry. Phenomenological psychiatry is not primarily interested in the phenomenon of psychiatric work (diagnosis and treatment) or in how psychiatric work appears to us in our immediate experience of it. Phenomenological psychiatry is primarily interested in how ideas and methods from phenomenology can be used in clinical practice and research in order to understand and help patients. Something similar is surely the case in nursing as well. Nurses don't simply engage with phenomenology in order to get a better understanding of the essence of the nursing phenomenon, but certainly also in order to offer better healthcare to the patients. Indeed, one of he reasons why phenomenology is of relevance is precisely because it offers ways to better understand the changed life situation of the patient.

But how to use phenomenology in nursing research? If we return to the way in which phenomenology has been and is used within the cognitive sciences, two specific areas come to mind: Data gathering and data analysis.

Although extensive clinical observations can certainly provide important insights, the data gathering will typically involve interviews. But how are these interviews to be conducted? One 
idea that has occasionally surfaced in the nursing literature is that the nurses have to be very careful in not asking any guiding questions. If the aim is to understand how particular events and life episodes are experienced by the individuals in question, it is important to allow the interviewees to express themselves about their own experience without being unduly influenced or constrained by the interviewer's research agenda. This is why Wood, for instance, suggests that "in true phenomenological research only one question is usually asked to elicit data" (Wood 1991: 196). Typically, the opening question will be quite broad and non-directive, and simply be a question that encourages the interviewee to start describing his or her experiences. If further questions are at all to be asked, then typically only to encourage the interviewee to keep talking (Beck 2013: 188-189).

This approach is confronted with one fairly obvious problem. What if the participants who are being interviewed and who are requested to provide rich descriptions of, say, what it is like to live with depression or chronic obstructive pulmonary disease, are only able to offer very coarse and superficial descriptions? Qualitative research certainly has resources available to deal with this specific challenge. But one can also find some interesting proposals within the cognitive science literature that is influenced by phenomenology. In some of his publications, Varela suggested that it might be possible to train the participants to gain greater intimacy with their own experiences, and consequently to become better observers and describers (Varela 1996). In a subsequent development of this approach, Petitmengin has argued that it is also possible to teach the interviewer to help guide the subject towards a progressive unfolding and expansion of her field of attention, such that hitherto unnoticed aspects and subtle details of her experience can be discovered and described (Petitmengin 2006). In short, it is not assumed that the interviewee is from the outset able to offer the relevant descriptions, and that the task of the interviewer is simply 
to register everything being said. Rather, the task of the interviewer is partially to help the interviewee obtain new insights of his or her own.

A different approach to the interview process, which, however, also involves a proactive and explorative engagement with the participants, can be found in phenomenological psychiatry. Based on many years of clinical work and an extensive familiarity with philosophical phenomenology, a group of researchers has developed a qualitative and semi-quantitative psychometric checklist containing 57 different items with the specific aim of allowing for a systematic and comprehensive clinical exploration of the patients' experiential life (Parnas et al 2005). Using the checklist to ask specific questions, the psychiatrists would conduct semistructured interviews and elicit descriptions from the patients regarding various experiential domains of particular relevance. This would, for instance, include bodily, temporal, and social dimensions, i.e., dimensions the significance of which have often been highlighted by phenomenological philosophers.

Both of these different approaches highlight the need for some very careful thinking about how to conduct a phenomenological interview. To adopt a hands-off approach, where one simply asks the patient to describe his or her experiences and then sits back and listens, is clearly not the right way. Moreover, although one should of course be prepared to revise one's theoretical assumptions in the face of what the patient is saying, a methodological prerequisite for doing the interview is by no means that one initially strips one's own mind of preconceived ideas. On the contrary, it is all about conducting the interview in light of quite specific ideas and notions, notions taken from phenomenological theory. To conduct a phenomenological interview is consequently not simply a question of being open-minded and interested in first-person experience. It is very 
much also about adopting and employing a comprehensive theoretical framework that will allow one to ask the right questions.

But what framework are we talking about? What notions are relevant? The selection should certainly not be made on the basis of veneration for the work of certain influential philosophers, but because the ideas in question can make a valuable difference, can allow for new insights or better therapeutic interventions. Consider, for instance, how phenomenological work on selfhood, empathy and embodiment in the past have led to a better understanding of the daily challenges of people living with schizophrenia, autism, stroke or cerebral palsy (Sass \& Parnas 2003, Zahavi \& Parnas 2003, Parnas et al. 2005, Klinke et al. 2015, Fuchs 2015, Martiny 2015, Zahavi \& Martiny 2019).

This might all sound fairly abstract, so let me be a bit more concrete and focus on a notion with immediate relevance for nursing, namely the lived body. How do phenomenologists approach the body? Supposedly by attending to the way it appears. But how is the body given? Is it primarily given as a perceptual object in space? That it can be given in such a way is evident from any anatomy lesson, but phenomenology has long insisted on the need for recognizing the difference between the body that is perceptually given as an object among many, and the body as it is subjectively lived through. Whereas the body as object captures how the body is apprehended from an observer's point of view, where the observer might be a scientist, a physician, or even the embodied subject herself, the notion of a subjective body captures the way the body is lived through from an embodied first-person perspective.

The distinction between the body as subject and the body as object is a phenomenological distinction. It is a distinction between two ways in which we can experience and understand the same body, and is not a distinction between two different bodies. A further claim made by many 
phenomenologists is that the lived body precedes the perceived body. In the first instance, I am not conscious of my body as an intentional object. I do not perceive it; I am it. Indeed, rather than simply being an object that I perceive in space, the body is precisely what allows me to perceive spatial objects in the first place. As Merleau-Ponty puts it, "far from my body being for me merely a fragment of space, there would be for me no such thing as space if I did not have a body" (Merleau-Ponty 2012: 104). Moreover, we do not observe the world from a distance, but are placed right in its middle, and the world reveals itself to us according to our bodily ways of inhabiting it.

The fact that the world is given to us as a world of affordances, i.e., as situations of meaning and circumstances for action, as allowing or preventing specific bodily activities, the fact that the body is operative in every perception and every action, the fact that it constitutes our point of view and our point of departure is, however, not something we normally attend to. When riding our bike or brushing our teeth, we seldom attend to our bodily skills. They remain in the background as something we can count on. But of course, this can quickly change, because of pain, exhaustion, illness or disability. What was previously taken for granted is suddenly problematized. As Carel writes,

cases of illness make apparent not only the bodily feeling of confidence, familiarity, and continuity that is disturbed, but also a host of assumptions that hang on it. For example, one's future plans depend on bodily capacities and thus are limited by ill health. One's temporal sense is radically changed by a poor prognosis. One's values and sense of what is important in life are frequently modified in light of illness; bodily limitations impact on one's existence generally (Carel 2013: 184). 
This is why we cannot simply view illness as something characterizing a less than perfect physiological machine. To understand illness, we need to understand how it affects the patient's being-the-world, e.g., his or her intentional, spatial, temporal and social sense-making. Consider, for example, how a person who finds himself bound to a wheelchair doesn't simply undergo a change in embodied self-experience. He finds the environment changed as well. What used to be an easily accessible storeroom in the basement might now appear as an inaccessible and unusable part of the house. In some cases, illness can also be identity transforming. A diabetic long-distance runner who loses her left foot due to gangrene might have to struggle with the task of redefining who she is, since the goals and activities that she used to consider identity defining are no longer available. Or consider somebody with locked-in syndrome, who is conscious and cognitively unimpaired, but paralyzed and unable to communicate verbally. In such circumstances, the body might well be experienced as an antagonist rather than as (part of) who I am.

These brief remarks only touch the surface of a phenomenological analysis of the body, but should make it evident, I hope, why such an analysis might be relevant to nurses, might aid them in understanding how illness or disability can affect the life of the patient (Leder 1990, Toombs 1992, Svenaeus 2000). A familiarity with phenomenological theorizing about the body can, however, not only help health care professional tailor their care to individual patients better; by using these phenomenological ideas in clinical practice, by being oriented towards and concerned with the life situation of concrete patients, by attending to specific aspects or dimensions that the phenomenological philosophers might have overlooked, the nurses can also contribute to theory development, and help refine the phenomenological analyses and distinctions. In the cognitive science literature, this situation has been labelled a relationship of mutual enlightenment (Gallagher 1997), since it isn't merely a question of importing and applying readymade ideas from 
philosophy to a given domain, rather in the best of cases it is a two-way exchange, where both sides can profit from the interaction.

A recent example of this in the domain of qualitative research can be found in Slatman and colleagues' study of how women cope with their mastectomy scars (Slatman et al 2016). Drawing on Husserl's, Sartre's and Merleau-Ponty's phenomenological analyses of the body, the authors suggest that it might be necessary to refine the phenomenological distinction between the body as object and the body as subject and reconsider the standard prioritization of the non-objectified body. As they argue, in some cases, nurses might actually help the patients deal with their illness or loss by adopting an objectifying perspective on the patient's body. By touching and investigating the mastectomy scars together with the patients, nurses might, for instance, help them regain a new sense of bodily normality (Slatman et al. 2016: 1623).

Importantly, in the article in question, Slatman and colleagues never refer to the epoché and the reduction. Indeed, why should they? As I have pointed out above, the epoché and the reduction are explicitly connected to very specific philosophical aims and pursuits. They are essential to Husserl's transcendental philosophical project. It is much less obvious that they are also notions that everybody seeking to apply phenomenology outside of philosophy must constantly bear in mind (Zahavi 2019c). Indeed, why should nurses who are interested in using phenomenology to provide better health care for, or do research on, mastectomy patients engage in this kind of exercise? To insist that the epoché and reduction are essential to any practice of phenomenology (cf. van Manen 2017a: 777, Giorgi 2012: 4) is neither theoretically justified nor conducive to the aims of qualitative research. Moreover, such claims have led to an abundance of publications filled with flawed and at times utterly strange accounts of the epoché and the reduction in their methodology section, and are also premised on a mistaken quest for purity. Whereas there 
might - perhaps - be an argument to be made for pursuing pure phenomenology within philosophy, the pursuit of purity in the context of applied phenomenology is a red herring. It is not coincidental that many of the principal figures in classical phenomenological psychology and psychiatry adopted a quite heterodox approach to phenomenology. I think they were right in doing so. Let me be even more provocative. Nurses, physiotherapists, psychologists, educators, psychiatrists, anthropologists, etc. who wish to draw on phenomenology should look to it not as a rigorous method, but as an open-minded attitude and theoretical toolkit that can be used in conjunction with a variety of methods.

\section{ACKNOWLEDGMENTS}

Thanks to Anthony Fernandez and Susanne Ravn for various helpful comments.

\section{NOTES}

1 One can find many other flaws and misinterpretations in van Manen's presentation of phenomenology. Commenting on the notion of 'transcendental', for instance, van Manen writes that "[t]transcendental means hidden", and then talks of how an external object like a die “'transcends' (escapes or hides) its ultimate being from our consciousness of it" (2014: 90). Not only does van Manen here succeed in conflating transcendental and transcendent, but he also manages to ascribe a Kantian view to Husserl that is utterly alien to Husserl's own philosophical outlook. For Husserl, transcendental subjectivity is not hidden, but intuitively graspable, and the being of transcendent objects are also not hidden, but precisely revealed in their manifestation for us ( Zahavi 2015, Zahavi 2017). 


\section{REFERENCES}

Beck, T.J. (2013). A phenomenological analysis of anxiety as experienced in social situations. Journal of Phenomenological Psychology, 44, 179-219.

Carel, H. (2013). Bodily doubt. Journal of Consciousness Studies 20/7-8, 178-197.

Carel, H. \& Meacham, D. (eds.) (2013). Phenomenology and Naturalism: Examining the relationship between human experience and nature. Cambridge: Cambridge University Press.

Carman, T. (2003). Heidegger's Analytic: Interpretation, Discourse and Authenticity in Being and Time. Cambridge: Cambridge University Press.

Colombetti, G. (2014). The Feeling Body: Affective Science Meets the Enactive Mind. Cambridge, Mass.: MIT Press.

Crotty, M. (1996). Phenomenology and Nursing Research. Melbourne: Churchill Livingstone.

Dreyfus, H. L. (1991). Being-in-the-World. Cambridge, Mass.: MIT Press. 
Dreyfus, H.L. (1993). Heidegger's Critique of the Husserl/Searle account of Intentionality. Social Research 60/1, 17-38.

Dwyer, P. (1990). Sense and Subjectivity: A Study of Wittgenstein and Merleau-Ponty. Leiden: Brill.

Fuchs, T. (2015). Pathologies of intersubjectivity in autism and schizophrenia. Journal of Consciousness Studies 22/1-2, 191-214.

Fuchs, T. (2017). Ecology of the Brain: The phenomenology and biology of the embodied mind. Oxford: Oxford University Press.

Gallagher, S. (1997). Mutual enlightenment: recent phenomenology in cognitive science. Journal of Consciousness Studies 4 (3): 195-214.

Gallagher, S. (2005). How the body shapes the mind. New York: Oxford University Press.

Gallagher, S., Zahavi, D. (2012). The Phenomenological Mind, $2^{\text {nd }}$ edition. London: Routledge.

Giorgi, A. (2012). The descriptive phenomenological psychological method. Journal of Phenomenological Psychology 43: 3-12. 
Husserl, E. (1970). The Crisis of European Sciences and Transcendental Phenomenology: An Introduction to Phenomenological Philosophy, trans. D. Carr. Evanston, IL: Northwestern University Press.

Husserl, E. (1989). Ideas Pertaining to a Pure Phenomenology and to a Phenomenological Philosophy. Second Book. Studies in the Phenomenology of Constitution, trans. R. Rojcewicz and A. Schuwer. Dordrecht: Kluwer Academic Publishers.

Husserl, E. (1999). The Idea of Phenomenology, trans. L. Hardy. Dordrecht: Kluwer Academic Publishers.

Husserl, E. (2001). Logical Investigations I-II, trans. J.N. Findlay. London: Routledge.

Jaspers, K. (1912). Die phänomenologische Forschungsrichtung in der Psychopathologie. Zeitschrift für die gesamte Neurologie und Psychiatrie 9: 391-408.

Klinke, M.E., Zahavi, D., Hjaltason, H., Thorsteinsson, B., Jónsdóttir, H. (2015). 'Getting the left right': The experience of hemispatial neglect after stroke. Qualitative Health Research 25: $1623-$ 1636.

Leder, D. (1990). The Absent Body. Chicago, IL: University of Chicago Press. 
Martiny, K.M.M. (2015). How to develop a phenomenological model of disability. Medicine, Health Care and Philosophy, 18: 553-565.

Merleau-Ponty, M. (2012). Phenomenology of Perception, trans. D. A. Landes. London: Routledge.

Parnas, J., Møller, P., Kircher, T., Thalbitzer, J., Jansson, L., Handest, P., and Zahavi, D. (2005). EASE: examination of anomalous self-experience. Psychopathology 38: 236-58.

Petitmengin, C. (2006). Describing one's subjective experience in the second person: an interview method for the science of consciousness. Phenomenology and the Cognitive Sciences 5: 229-69.

Petitot, J., Varela, F. J., Pachoud, B., and Roy, J.-M. (eds.) (1999). Naturalizing Phenomenology Stanford, Calif.: Stanford University Press.

Ratcliffe, M. (2008). Feelings of Being: Phenomenology, psychiatry and the sense of reality. Oxford: Oxford University Press.

Reinach, A. (1968). What is phenomenology? trans. D. Kelly. The Philosophical Forum 1: 234256. 
Roulston, K. (2018). Book Review: Mark D Vagle, Crafting Phenomenological Research and Max Van Manen, Phenomenology of Practice: Meaning-Giving Methods in Phenomenological Research and Writing. Qualitative Research, 18: 250-253.

Sartre, J.-P. (2018). Being and Nothingness, trans. S. Richmond. London: Routledge.

Sass, L. and Parnas, J. (2003). Schizophrenia, consciousness, and the self. Schizophrenia Bulletin 29: 427-444.

Scheler, M. (1973). Die deutsche Philosophie der Gegenwart, in M. S. Frings (eds.): Gesammelte Werke VII, pp. 259-326. Bern and Munich: Francke-Verlag.

Slatman, J., Halsema, A. \& Meershoek, A. (2016). Responding to Scars After Breast Surgery Qualitative Health Research, 26: 1614-1626

Smith, J. A. (1996). Beyond the divide between cognition and discourse: Using interpretative phenomenological analysis in health psychology, Psychology \& Health, 11(2), 261-271.

Smith, J.A. \& Osborn, M. (2008). Interpretative phenomenological analysis. In J.A. Smith (Ed.) Qualitative Psychology: A practical guide to research methods (pp. 53-80). London: Sage.

Smith, J.A., Flowers, P., Larkin, M. (2009). Interpretative Phenomenological Analysis: Theory, Method and Research. London: Sage. 
Svenaeus, F. (2000). The Hermeneutics of Medicine and the Phenomenology of Health: Steps towards a Philosophy of Medical Practice. Dordrecht: Kluwer.

Thompson, E. (2007). Mind in Life: Biology, Phenomenology, and the Sciences of Mind. Cambridge, Mass.: Harvard University Press.

Toombs, S. K. (1992). The Meaning of Illness: A Phenomenological Account of the Different Perspectives of Physician and Patient. Dordrecht: Kluwer.

van Manen, M. (1990). Researching Lived Experience: Human Science for an Action Sensitive Pedagogy. London, ON, Canada: Althouse Press.

Van Manen, M. (2014). Phenomenology of Practice: Meaning-giving methods in phenomenological research and writing. Walnut Creek, CA: Left Coast Press.

van Manen, M. (2017a). But is it phenomenology? Qualitative Health Research 27: 775-779.

van Manen, M. (2017b). Phenomenology it its original sense. Qualitative Health Research 27: $810-825$.

van Manen, M. (2018). Rebuttal rejoinder: Present IPA for what it is-Interpretative psychological analysis. Qualitative Health Research 28: 1959-1968. 
van Manen, M. (2019). Rebuttal: Doing phenomenology on the things. Qualitative Health Research 29: 908-925.

Varela, F.J. (1996). Neurophenomenology: a methodological remedy for the hard problem. Journal of Consciousness Studies 3(4): 330-49.

Varela, F.J. (1997). The naturalization of phenomenology as the transcendence of nature: searching for generative mutual constraints. Alter 5: 355-81.

Varela, F.J., Thompson, E., and Rosch, E. 1991. The Embodied Mind: Cognitive Science and Human Experience. Cambridge, Mass.: MIT Press.

Wood, F.G. 1991. The meaning of caregiving. Rehabilitation nursing 16/4, 195-198.

Zahavi, D. 2003. Husserl's Phenomenology. Stanford: Stanford University Press.

Zahavi, D. 2004. Phenomenology and the project of naturalization. Phenomenology and the Cognitive Sciences 3(4): 331-47.

Zahavi, D. 2005. Subjectivity and Selfhood: Investigating the first-person perspective. Cambridge, Mass.: MIT Press. 
Zahavi, D. 2014. Self and Other: Exploring Subjectivity, Empathy, and Shame. Oxford: Oxford University Press.

Zahavi, D. 2015. Husserl and the Transcendental. In S. Gardner \& M. Grist (eds.): The Transcendental Turn, pp. 228-243. Oxford: Oxford University Press.

Zahavi, D. 2017. Husserl's Legacy: Phenomenology, Metaphysics, and Transcendental Philosophy. Oxford: Oxford University Press.

Zahavi, D. (2019a). Phenomenology: The Basics. London: Routledge.

Zahavi, D. (2019b). Getting it quite wrong: van Manen and Smith on phenomenology. Qualitative Health Research 29(6): 900-907.

Zahavi, D. (2019c). Applied phenomenology: Why it is safe to ignore the epoché. Continental Philosophy Review, in press.

Zahavi, D. and Parnas, J. (2003). Conceptual problems in infantile autism research: Why cognitive science needs phenomenology. Journal of Consciousness Studies 10/9, 53-71.

Zahavi, D., Martiny, K.M.M. (2019). Phenomenology in nursing studies: New perspectives. International Journal of Nursing Studies 93: 155-162. 